\title{
JUVENTUDE E MIGRAÇÃO INDÍGENA ESTUDANTIL E AS POLÍTICAS PÚBLICAS DE INGRESSO E PERMANÊNCIA NA UNIVERSIDADE
}

\author{
INDIGENOUS STUDENT YOUTH AND MIGRATION AND PUBLIC POLICIES \\ FOR UNIVERSITY ADMISSION AND RETENTION
}

\author{
JUVENTUD Y MIGRACIÓN INDÍGENA ESTUDIANTIL Y LAS POLÍTICAS \\ PÚBLICAS DE INGRESO Y PERMANENCIA EN LA UNIVERSIDAD
}

\section{Resumo}

Ao observar a dinâmica do cotidiano acadêmico dos estudantes indígenas, decidi trilhar certos caminhos de interpretação que concernem ao pertencimento indígena, à experiência juvenil e às políticas de ações afirmativas voltadas para o ensino superior e direcionadas a esse público, no Brasil. Articular tais percepções me levou a refletir sobre políticas públicas para o ingresso e permanência no ensino superior e a consequente migração de jovens indígenas para centros urbanos, cujo foco da observação e, consequentemente, da análise, são os próprios estudantes universitários e o seu protagonismo para enfrentar as vicissitudes da vida universitária. Parto do suposto de que a partir do fenômeno da migração haverá a transcendência para outras realidades juvenis que passarão a vivenciar, por força das próprias trocas, materiais e simbólicas. Dessa forma, a minha intenção, foi problematizar as implicações da migração estudantil indígena para Salvador, ao ingressarem na Universidade Federal da Bahia (UFBA), identificando quais estratégias são utilizadas para a ocupação da cidade e quais as relações que persistem com as comunidades de pertencimento para a manutenção dos laços comunitários. No Brasil e na América Latina, essa nova forma de migração característica da juventude estudantil configurará um novo formato de ocupação das cidades pelas populações indígenas.

Palavras-chave: estudantes indígenas, universidade, juventude, migração, ações afirmativas. 


\begin{abstract}
Having observed the dynamics of the academic daily life of the indigenous students, I decided to follow certain paths of interpretation that concern indigenous belonging, the experience of youth, and affirmative action policies aimed at higher education and this population in Brazil. Articulating such perceptions led me to reflect on public policies for admission to and permanence in higher education and the consequent migration of indigenous youth to urban centres. The focus of observation - and consequently of analysis - is the students themselves and their protagonism in facing the vicissitudes of university life. The study bases itself in the supposition that from the phenomenon of migration the students will transcend to other realities of youth that they will come to experience through their own material and symbolic exchanges. Thus, my intention was to problematize the implications of indigenous student migration to Salvador upon acceptance to the Federal University of Bahia (UFBA), identifying which strategies are used for the occupation of the city and which relationships persist with communities of belonging in maintaining community bonds. In Brazil and Latin America this new form of migration characteristic of student youth will shape a new format of city occupation by indigenous populations.
\end{abstract}

Keywords: indigenous students, university, youth, migration, affirmative action.

\title{
Resumen
}

Al observar la dinámica del cotidiano académico de los estudiantes indígenas decidí recorrer ciertos caminos de interpretación que conciernen a la pertenencia indígena, a la experiencia juvenil y a las políticas de acciones afirmativas dirigidas a la enseñanza superior y a ese público en Brasil. Articular tales percepciones me llevó a reflexionar sobre políticas públicas para el ingreso y permanencia en la enseñanza superior y la consiguiente migración de jóvenes indígenas a centros urbanos, cuyo foco de observación y, consecuentemente, de análisis, son los propios estudiantes universitarios y su protagonismo en el afrontamiento a las vicisitudes de la vida universitaria. Parto del presupuesto de que a partir del fenómeno de la migración habrá un trascendencia de los estudiantes para otras realidades juveniles que pasan a vivir, por fuerza de intercambios materiales y simbólicos. De esa forma, mi intención fue problematizar las implicaciones de la migración estudiantil indígena hacia Salvador al ingresar a la Universidad Federal de Bahía (UFBA), identificando qué estrategias se utilizan para la ocupación de la ciudad y cuáles son las relaciones que persisten con las comunidades de pertenencia para el mantenimiento de los vínculos comunitarios. En Brasil y en América Latina esta nueva forma de migración característica de la juventud estudiantil configurará un nuevo formato de ocupación de las ciudades por las poblaciones indígenas.

Palabras clave: estudiantes indígenas universidad, juventud, migración, acciones afirmativas. 


\section{Introdução}

Terra alheia, terra alheia. A minha terra não é aqui, é na minha aldeia"

(Canto Tuxá)

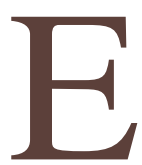

ste canto tuxá, sempre entoado pelos estudantes indígenas nas atividades realizadas na universidade, simboliza a relação "temporária" que pretendem estabelecer com Salvador, a capital do estado da Bahia, e, consequentemente, com a Universidade Federal da Bahia (UFBA). O presente artigo ${ }^{1}$ abordará a condição desses jovens ${ }^{2}$ estudantes indígenas e de como a migração para a capital faz com que vivenciem, agora como universitários, o cotidiano produzido pela urbanidade de uma metrópole até então desconhecida, para a maioria. Destaco que a classificação desses estudantes enquanto jovens, o é de acordo com a sua auto-

\footnotetext{
${ }^{1}$ Este artigo é uma adaptação e atualização do capítulo "Migração indígena juvenil estudantil", da tese de doutorado intitulada "Passou? Agora é luta!": um estudo sobre ações afirmativas e a presença de jovens estudantes indígenas na Universidade Federal da Bahia, defendida em 2016, no Programa de Pós-Graduação em Antropologia (PPGA), da Universidade Federal da Bahia (UFBA), orientada pela $\operatorname{Prof}^{\mathrm{a}} \mathrm{Dr}^{\mathrm{a}}$ Maria Rosário Gonçalves de Carvalho (UFBA).
}

${ }^{2}$ Para Pierre Bourdieu o acesso aos processos de escolarização contribuem para a oposição entre jovens de classe diferente, e, ao mesmo tempo, uma parte dos jovens, biologicamente falando, que até então não tinha acesso à adolescência, passa a descobrir este status temporário, "meio-criança, meio-adulto"; "nem criança, nem adulto". Desse modo, diferentes classes sociais tiveram acesso, de maneira proporcionalmente mais relevante, ao ensino secundário, considerado um fato social classificação, em um espectro etário que varia dos 17 aos 31 anos. Parto do suposto de que a partir do fenômeno da migração ${ }^{3}$ haverá a transcendência para outras realidades juvenis que passarão a vivenciar, por força das próprias trocas, materiais e simbólicas. A migração viabilizará, nesse caso, a qualificação juvenil, o que esteve diretamente relacionado, na última década, ao incremento da assistência escolar mediante as políticas públicas voltadas para as populações etnicamente diferenciadas, especialmente aquelas voltadas para o ensino superior.

Dessa forma, a minha intenção, é a de problematizar as implicações da migração estudantil indígena para Salvador e a UFBA, identificando quais estratégias são utilizadas para a ocupação da cidade e quais as relações que persistem com as comunidades de pertencimento para a manutenção dos laços comunitários e como as políticas públicas de

muito importante. Mesmo nos meios aparentemente mais distanciados da condição estudantil do século XIX, isto é, na pequena aldeia rural, onde os filhos dos camponeses ou artesãos frequentam o ginásio local, mesmo neste caso, os adolescentes são colocados, durante um tempo relativamente longo, numa idade em que anteriormente eles estariam trabalhando em posições quase exteriores ao universo social que define a condição de adolescente (Bourdieu, 1983).

${ }^{3}$ Ismael Tcham (2016) desenvolveu uma pesquisa no Programa de Pós-Graduação em Antropologia da Universidade Federal de Pernambuco sobre a imigração acadêmica de jovens estudantes africanos deslocados para universidades brasileiras, denominando de nova diáspora africana no Brasil essa nova onda de imigrantes universitários. O seu recorte de estudo compreende os estudantes imigrantes africanos que se fixaram nas regiões metropolitanas do nordeste. 
permanência e assistência na Universidade participam dessa migração.

\section{Juventudes indígenas contemporâneas}

Ao decidir participar da I Bienal Latinoamericana de Infancias y Juventudes ${ }^{4}$, no ano de 2014, em Manizales, na Colômbia, reafirmei as minhas impressões iniciais de que o grupo que eu estava pesquisando se enquadra no perfil de “juventudes indígenas contemporâneas" (García Álvarez, 2012), tema ainda muito pouco tratado na literatura antropológica brasileira. Desse modo, ao reunir os dados pesquisados percebi que o grupo se caracteriza para além da condição de estudantes indígenas, mas por uma “maneira de ser jovem e indígena em um contexto metropolitano contemporâneo" (García Álvarez, 2012).

A entrada na universidade faz emergir, nas comunidades indígenas, uma população juvenil estabelecida nas metrópoles, como Salvador, que passa a estruturar e configurar suas práticas sociais, culturais e representações sob certa influência dessa nova realidade de significados que a vida na cidade

\footnotetext{
${ }^{4}$ A I Bienal Latinoamerican de Infancias y Juventudes - Democracias, Derechos Humanos y Ciudadanías, ocorreu em Manizales, Colômbia, de 17 a 21 de 2014. A Mesa em que apresentei a comunicação foi "Formaciónuniversitaria de sectores emergentes en América Latina: políticas para igualdad de oportunidades y apropiaciones de las juventudes múltiples".
}

proporciona (Urteaga, 2011, 2010 e 2007, apud García Álvarez, 2012).

Desse modo, essa população prossegue reproduzindo padrões culturais tradicionais não incompatíveis com a nova configuração residencial, tais como organização religiosa, reprodução da unidade familiar, afiliação étnica e sentimento de apego sócio-territorial de origem. Assim, os estudantes migrantes se apropriam, valoram e legitimam o espaço urbano a partir do território de origem e através da memória coletiva (Farfán, Castillo y Fernández, 2003 apud García Álvarez, 2012).

\section{Luis Fernando García Álvarez} problematizou, em sua dissertação de mestrado $^{5}$ sobre jovens estudantes indígenas no México, algumas questões que considero também pertinentes ao contexto dos estudantes que pesquiso. O referido autor tratou do que tem sucedido com as novas gerações de migrantes indígenas em áreas metropolitanas, o que representa viver neste contexto, bem como o que representa ser jovem e indígena (García Álvarez, 2012, p. 14). Suponho poder aproximar as suas considerações de uma problematização da

\footnotetext{
${ }^{5}$ Projeto de dissertação de mestrado Antropologia Social denominado: "Jóvenes indígenas en contextos metropolitanos. La construcción de lo juvenil en una comunidadmixtecaenel Área Metropolitana de Monterrey, Nuevo León”.
} 
construção da condição de indígena juvenil dentro das comunidades de origem e em metrópoles como Salvador/BA.

García Álvarez toma como hipótese de sua investigação que esses jovens experimentam um dinâmico e complexo processo de trocas e transformações sociais, econômicas, políticas e culturais que impacta, indubitavelmente, a multidimensionalidade das suas vidas cotidianas. Diante desse contexto singular e diferenciado, o trabalho antropológico ganha sentido mediante a descrição e compreensão das realidades particulares contemporâneas, sendo a intenção do autor abordar a perspectiva juvenil a partir de um enfoque interpretativo, para se aproximar da complexidade que caracteriza a construção do jovem indígena contemporâneo em um contexto metropolitano específico (García Álvarez, 2012, p. 14-15).

Como os jovens indígenas estão modelando a sua condição juvenil entre as comunidades de pertencimento e os novos nichos urbanos? Como suas expectativas e planos de futuro, orientados, doravante, em interação com as percepções/concepções dos seus pares não indígenas e instituições regionais estão sendo gestados?

Em minha pesquisa, assim como na pesquisa realizada por García Álvarez, um dos objetivos foi, pois, conhecer a construção da condição juvenil dos estudantes, com a finalidade de identificar as formas como os jovens estão configurando a situação de contato interétnico; registrar como significam e contextualizam a vida nos nichos urbanos; como são visualizadas as noções de juventude e juventude indígena; identificar e descrever os espaços sociais do jovem, desde as posições de fronteira que constroem em âmbito familiar, comunitário, como em contexto metropolitano; identificar seus interesses, expectativas, medos, preocupações, desafios e planos de futuro desde as experiências e tensões vinculadas aos contextos local e global. Como afirma García Álvarez,

En particular se trata de radicalizar la mirada al objeto jóvenes indígenas contemporáneos, emplazándolos en sus variados lugares intersecciones transitadas por múltiples líneas (variables) estructuradoras (_)-, para leer desde allí como están: 1) participando activamente em laconfiguración de estas zonas fronterizas y 2) dotando de contenidos y sentidos diversos tanto su experiencia juvenil como su etnicidad. Cabe resaltar que em el caso de los jóvenes indígenas contemporáneos, al estigma de ser indio se agreganlos problemas derivados de su condición etaria, la cual comparten com otros sectores de la población nacional joven, es decir, la necesidad de definir pertenencias, afinidades culturales y proyectos de vida enun contexto em el que prevalecen la crisis económica, la falta de empleo y una inmensa e indiscriminada oferta cultural y de consumo propagada por los medios de comunicación masiva (García Álvarez, 2012, p. 22). 
García Álvarez faz, em sua investigação, uma diferenciação entre o conceito de juventude indígena como elaboração teórica e juventudes indígenas como o correlato empírico particular e heterogêneo. As juventudes indígenas migrantes delimitam uma categoria que engloba jovens, homens e mulheres de diferentes grupos indígenas em deslocamento, que se definem a partir do deslocamento territorial orientado para a troca de residência, agora motivada pelos estudos. Desse modo, García Álvarez concorda que homens e mulheres indígenas na condição de estudantes universitários se apropriam, cada vez mais, do direito a serem jovens, a viverem uma etapa intermediária entre a infância e a vida adulta, quando, geralmente, nem sempre é uma etapa vivenciada, nesses termos, nas comunidades tradicionais indígenas (Ib., p. 23).

Um ponto central na dissertação é a reflexão do autor sobre qual é o sentido das práticas sócio-culturais na emergência de novos atores no seio das comunidades indígenas migrantes, o que requer que, na condição de pesquisador, desloque seu olhar para os diferentes tipos de ação social, sociabilidade e reprodução que fazem parte do cotidiano desses jovens (Ib., p. 23). Neste

\footnotetext{
${ }^{6}$ Norbert Elias identifica os papéis de estabelecidos e outsider, a partir da análise dos moradores de um bairro industrial inglês. $\mathrm{O}$ outsider representa os recém-chegados, que, nessa condição, tentam fazer parte de grupos com tradições já estabelecidas, que
}

contexto, ele investiga o processo de construção e a especificidade da juventude na comunidade Mixtec, a partir dos paradigmas juvenil e de agenciamento, especialmente considerando que os jovens indígenas que estão nas cidades, expressam as tensões, dilemas e escolhas que enfrentam sobre suas identidades, lealdades e pertences futuros.

Baseado nessas abordagens, García Álvarez considerou relevante propor o termo, tido como operacional, "juventude indígena metropolitana" como uma contribuição para a discussão. Para ele, falar da juventude indígena metropolitana responde à intenção de dar conteúdo etnográfico ou empírico para essa categoria a partir das práticas e significados da juventude apreendidos a partir do desenvolvimento do trabalho de campo, num contexto de agentes específicos. Não obstante, ele ressalta que é necessário prestar atenção à diversidade e desigualdade de condições que moldam jovens indígenas em um contexto contemporâneo metropolitano, como migrantes que continuam a pertencer à comunidade de origem e, ao mesmo tempo, a serem vistos como outsiders ${ }^{6}$, podendo ainda surgir tensões especiais com parentes, amigos e autoridades, uma vez retornem ao

podem ser grupos mais poderosos com crenças, costumes e sensibilidades distintas dos seus, ou são forçados ao convívio a partir de uma interdependência (Elias, 2000). 
local de origem (Pérez Ruiz, 2004:82 apud García Álvarez, 2012, p. 23/24).

Natelson Souza, em sua dissertação de mestrado ${ }^{7}$, investigou "o que é ser jovem índio Xokó na vida contemporânea da terra indígena”. Empreendeu uma discussão sobre estudos em antropologia da juventude, particularmente a indígena, tendo em vista os jovens índios Xokó, suas aspirações e agências perante um mundo em constante transformação.

Em vez de enquadrar o "ser jovem" ou caracterizar um "discurso de jovem", localiza os atores jovens da pesquisa numa rede social para, a partir das suas narrativas, tecer uma compreensão antropológica sobre como eles se articulam entre o conjunto de parentes estabelecido na Ilha de São Pedro (SE) (SOUZA, 2011, p. 15).

A dissertação tenta não cair na armadilha de essencializar a identidade do jovem Xocó, buscando, ao invés, perceber como esses jovens articulam sua herança cultural na construção da identidade, compreendendo que o seu espaço interpretativo "é constituído entre o presente e o passado (...) entre o espaço de

7 A dissertação, intitulada "A HERANÇA DO MUNDO: história, etnicidade e conectividade entre jovens Xokó", estabelecidos em Porto da Folha/SE, foi defendida em 2011, no Programa de Pós- constituição de parentalidade e socialidade vivida" (Ib. p. 19).

O autor parte do suposto de que os mais jovens:

estão social e culturalmente inseridos numa fase de inovação da vida coletiva em todos os seus âmbitos, através de seus projetos e modos de ação no mundo. Os projetos a que me refiro, nesse contexto da fala dos jovens, podem ser classificados em dois tipos, ou seja, os que visam a um movimento na direção do exterior e os que visam a uma permanência no interior, na comunidade. Os primeiros, para serem concretizados, levam os jovens à migração para outras localidades, por exemplo, a fim de continuação dos estudos e trabalhos inexistentes na Ilha. Os segundos, no entanto, são indissociáveis da cultura indígena emblemática, i.e., aquela que destaca a administração dos signos de indianidade por estes estarem relacionados estreitamente às políticas de identidade na relação com o Estado (p. 22).

Os estudantes indígenas universitários estão inseridos nesse projeto que Natelson Souza caracteriza como visando movimento na direção do exterior, uma vez que, ao serem aprovados em um curso, terão que se deslocar, passando a experimentar um novo processo social e

Graduação em Antropologia da Universidade Federal da Bahia. 
urbano. E mesmo empreendendo projetos e modos de ação distintos, esses jovens tendem a não querer abrir mão da cultura indígena vivenciada em suas comunidades, como assim também percebo entre os estudantes indígenas da UFBA residentes em Salvador, "o que transparece quando falam dos seus engajamentos nas atividades que levam à construção social diária da rede de parentes" (Souza, 2011, p. 22).

Mariana Paladino buscou, em sua tese $^{8}$, explicar o processo de escolarização experimentado pelos Ticuna, "o que envolve entender suas ideais, crenças e representações culturais, a atuação de diversas agências e agentes (Estado, missões, organizações não-governamentais, universidades, antropólogos) e a constituição de um movimento indígena ticuna, entre outros". Ao estudar tal processo de escolarização, Paladino pode perceber como os diversos deslocamentos e percursos por eles realizados, a exemplo das viagens e da convivência no espaço urbano, foram representados por esses atores como instâncias de aprendizagem, sendo apoiados

\footnotetext{
8 Mariana Paladino defendeu a tese intitulada "Estudar e experimentar na cidade: trajetórias sociais, escolarização e experiência urbana entre “jovens" indígenas ticuna, Amazonas" em 2006, no Programa de Pós-Graduação em Antropologia Social, Museu Nacional, da Universidade Federal do Rio de Janeiro.
}

por redes de parentesco, compadrio e aliança política (2006, p. 8).

Esta tese aponta, pois, para o entendimento do processo de formação vivido por um segmento da população Ticuna em um meio não-indígena, para as motivações que o orientam, como esse grupo posiciona-se diante da necessidade de se preparar para "os tempos modernos", e que lugar ocupa na sociedade ticuna (Paladino, 2006, p.8).

Assim como Paladino acompanhou os estudantes indígenas Ticuna pelo cotidiano fora da escola, nos seus percursos pelas cidades de Benjamim Constant e São Paulo de Olivença (2006, p. 11), eu também comprovei que "o espaço urbano revelava-se para eles como uma instância de aprendizagem que possibilitava experiências e o estabelecimento de novas relações" ( $I b$. p. 11). Igualmente, nas conversas mantidas com os estudantes o que mais se revelava interessante eram temáticas relacionadas à esfera externa à universidade, "que não estivessem só voltadas à aquisição de conteúdos escolares, e sim aquelas que diziam respeito às suas celebrações, festas e 
atos escolares, ou seja, aos eventos vinculados à possibilidade de socialização, lazer e diversão" (Ib.11). Por isso, nesses mais de dez anos de pesquisa (2005-2016), além do espaço acadêmico das salas, corredores, pátios, a etnografia que empreendi desenvolver fez com que acompanhasse esses jovens no seus momentos de lazer, nas festas, nas formaturas, nos momentos de descontração.

Paladino aborda e analisa as características e os traços fundamentais que adquire o fenômeno do deslocamento para a cidade, para fins de estudo, praticado pelos estudantes Ticuna. Ela constatou que as motivações que os orientam na escolha do estudo na cidade é determinada conforme as diferentes posições sociais e configurações ideológico-religiosas dos estudantes e seus parentes, como a de se "civilizar", a de "conhecer o mundo dos brancos", a de ter acesso a uma "melhor educação" (Ibid. p. 110). Para alcançar os objetivos da tese, analisa as narrativas referentes aos percursos escolares de uma professora e um estudante Ticuna quanto à motivação pela formação escolar e experiência de estudo na cidade de Benjamim Constant.

Antonella Tassinari e os pesquisadores Edwiges Ioris, José de Almeida e Suzana de Jesus, ao analisarem a trajetória escolar dos estudantes indígenas matriculados na Universidade Federal de
Santa Catarina (UFSC), até 2010, constataram que os egressos eram oriundos de escolas públicas de contexto urbano. A partir de 2011 é que começaram a ingressar estudantes oriundos de escolas indígenas e residentes nas aldeias, dado que o Programa de Ações Afirmativas da UFSC tem início em 2008. Para os pesquisadores, essa constatação demonstra que o referido Programa está conseguindo acolher, muito timidamente, os estudantes indígenas formados nos cursos de ensino médio oferecidos em suas aldeias, privilegiando aqueles já com experiência de formação e residência em contexto urbano. Os estudantes, por sua vez, alegam que todo o processo para o ingresso é bastante complexo para eles, já que envolve a solicitação de isenção de taxa de inscrição até a realização das provas, tornando-se, às vezes, inacessível para os candidatos que estudam e residem nas comunidades (Tassinari et al, 2013, p. 229). Essas alegações serão encontradas em praticamente todas as seleções para estudantes indígenas, com ingresso diferenciado, das universidades brasileiras.

$\mathrm{Na}$ pesquisa realizada, Tassinari (et al, 2013) afirmam que em muitos relatos dos estudantes indígenas que ingressaram na UFSC há referência a problemas em afastarse da família e da comunidade, dificuldades econômicas e sentimento de falta de preparo 
para a realização da prova para seleção no vestibular e, mesmo para quem ingressa, para acompanhar os cursos escolhidos. Esses são os principais pontos em comum. Para os autores, há de se considerar que a relação que estudantes indígenas, principalmente aqueles que vivem em aldeias, estabelecem com o urbano e com a própria universidade difere, de forma significativa, das relações que estudantes não-indígenas mantêm com estes contextos (Ibid. p. 231).

O ideal de sair de casa para estudar e alcançar autonomia financeira e independência pessoal, que geralmente motiva os estudantes universitários em busca de uma carreira profissional, não necessariamente é o que mobiliza os estudantes indígenas. Estudar para ter uma profissão e um bom salário é uma meta que vai ao encontro das práticas sociais das chamadas sociedades complexas e das camadas médias urbanas. Esta lógica centrada nos projetos individuais, na manutenção da família nuclear, na preparação para o mercado de trabalho nos moldes capitalistas, não é a mesma que tem direcionado os estudantes indígenas para o Ensino Superior, mesmo que a busca por profissionalização siga as mesmas trilhas dos estudantes não indígenas (p. 231).

Para os mesmos autores, é necessário considerar que a solidão e a falta da família como obstáculos para a superação da evasão possam parecer estranhas no contexto universitário contemporâneo das sociedades ocidentais, onde a autonomia, a individualidade e a independência são características valorizadas e estimuladas. Todavia, entre os indivíduos pertencentes às sociedades tradicionais, como as indígenas, em que o parentesco tem profunda influência na vida produtiva, na organização política e nas dinâmicas de produção e circulação de conhecimentos, por certo afastar-se da família e da comunidade é uma tarefa extremamente difícil (Tassinari et al, 2013, p. 231-2). É o que confirma o relato de Iara Brandão, estudante pataxó do curso de engenharia de controle, ao reportar o que significou para ela "a experiência de sair de casa, da minha raiz, minha cultura e ir para um centro urbano com tanta coisa diferente a que eu não estava acostumada foi algo transformador em minha vida, em vários aspectos. No começo, a insegurança e imaturidade nos fazem duvidar dos nossos objetivos e se somos realmente capazes".

As questões até aqui problematizadas quanto ao deslocamento dos estudantes e às especificidades de como vivenciam o período da juventude nem sempre são levadas em consideração na elaboração de políticas públicas voltadas para as populações tradicionais, que parecem ter em mente um tipo ideal de jovem urbano que poderá estar bastante distante da realidade indígena, ou não contemplará as demandas específicas 
reivindicadas por esta juventude.

Vale salientar que esses jovens indígenas têm se organizado e constituído representações, redes $^{9}$, especialmente a partir do movimento estudantil indígena, a exemplo da participação na III Conferência Nacional da Juventude, que ocorreu em 2015, em Brasília. A organização do movimento estudantil por parte de jovens indígenas defende "políticas públicas para os povos indígenas sem intermediários", o que justifica a necessidade de ingresso de indígenas nas universidades. $\mathrm{O}$ que $\mathrm{o}$ movimento indígena destaca é que a organização política estudantil não indígena é partidária, sendo "aparelhada" por partidos políticos ao longo da história do movimento estudantil, diferentemente do movimento estudantil indígena que ainda não se tornou partidário, lutando em prol da causa indígena nacional. Na UFBA, o Núcleo de Estudantes Indígenas (NEI) representa a mobilização política que tem caracterizado a participação da juventude indígena que ingressou na universidade a partir das ações afirmativas. O NEI é uma organização interna dos estudantes indígenas, que tem acompanhado o seu ingresso e permanência junto aos setores da universidade. Apesar de se tratar de uma organização recente, tem mobilizado

\footnotetext{
${ }^{9} \mathrm{Na}$ internet, nas redes sociais, como no Facebook, serão criadas comunidades como a Rede de Juventude Indígena (REJUIND), criada no I Seminário Nacional de Juventude, que ocorreu em
}

boa parte dos estudantes indígenas aldeados, no sentido de produzir interlocuções com os vários setores da universidade, em uma estratégia de reivindicação e colaboração com as instâncias institucionais.

Quando comecei a analisar os dados produzidos ao longo da pesquisa, fui percebendo como certos detalhes, comportamentos, regras de ocupação do espaço que configuravam um certo modo particular de vivenciar a experiência de indígena, jovem, estudante e universitário, teriam sido influenciados, mesmo que indiretamente, pelas políticas de ações afirmativas da UFBA. Dessa forma, decidi por apresentar e examinar algumas das relações e comportamentos constituídos em Salvador pelos interlocutores, na condição de indígena, jovem, estudante e migrante. A produção dessas narrativas foi realizada no trabalho de campo, a partir de entrevistas, diálogos e observações, enquanto que a seleção e construção do repertório para a análise foram orientadas pelas próprias narrativas, conversas, observações, comparações que foram traçando e identificando as particularidades, de modo que reproduzissem, de forma mais espontânea, e nem sempre linear, o cotidiano dos estudantes na cidade, por meio de uma

Brasília, em 2009. Surge como ferramenta para facilitar a informação e comunicação entre a diversidade de juventudes indígenas. 
escrita etnográfica descritiva.

\section{A ocupação da cidade a partir do cordão com a comunidade}

Um vez em Salvador, os estudantes residem, primeiramente, com parentes ou amigos da família, como medida que lhes proporcione adaptação à cidade e menos despesas. O que se percebe é que a migração para Salvador, nesses casos, suscita forte preocupação com a manutenção dos laços com os familiares e a comunidade de pertencimento. Como assinalado por Paladino, as migrações impulsionadas por trajetórias escolares de um segmento da população Ticuna possuem grande diferença quanto ao que sustentam as ideias sobre "aculturação" ou "destribalização" dos índios no contexto urbano (Paladino, 2006, p. 127), já que esses estudos “destacam que com a migração se perdem raízes e laços com a família ou com a comunidade de origem, resultando daí, em nível social, uma desorganização do grupo de parentesco e, em nível individual, personalidades desagregadas". Ou, como salienta Oliveira:

Um modo simplista de pensar sobre os movimentos migratórios que envolvem as sociedades indígenas costuma interpretar tais deslocamentos como indícios de que está em marcha um processo de desagregação destas sociedades. Toma-se como ponto de partida uma meia verdade - a de que o índio e seu território mantêm uma relação visceral - para daí inferir que qualquer dissociação desta fórmula (que como bandeira de luta é didática e até mesmo em muitos casos eficiente) implicará em risco de extinção ou em grave prejuízo para aquelas coletividades (Oliveira, 1996, p.6 apud Paladino, p.128).

Albuquerque (2011), por sua vez, chama a atenção para o fato de que boa parte dos dados sobre população indígena urbana advém de pesquisas pontuais de organizações não governamentais, alguns órgãos públicos e trabalhos acadêmicos, causando surpresa a incipiente produção acadêmica sobre o tema. Ele lembra que no campo da antropologia os primeiros trabalhos sobre a questão dos indígenas nas cidades foram realizados por Roberto Cardoso de Oliveira sobre os Terena (Urbanização e Tribalismo: a integração dos Índios Terena numa sociedade de classes; e Urbanização sem assimilação: estudo dos Terena destribalizados, 1968 e 1958), seguidos por mais alguns trabalhos sob sua orientação. Afirma que, mais recentemente, a temática ganhou mais evidência nos fóruns especializados em antropologia e nas ciências sociais, de modo geral. Destaca, em especial, o interesse de João Pacheco de Oliveira, que, em seu memorial para concurso de professor titular do Museu Nacional/UFRJ (1999), revela o desejo de conduzir pesquisas sobre a população indígena desterritorializada, buscando compreender as razões para a 
continuidade cultural dessas populações. Já na esfera pública, a questão dos indígenas nas cidades aparece oficialmente, segundo Albuquerque, na Conferência Nacional dos Povos Indígenas, em 2006, com a aprovação e inclusão de um capítulo sobre índios urbanos (Albuquerque, 2011, p. 69-70).

Diversos estudos sobre etnicidade em contextos urbanos e que envolvem processos migratórios, em comunidades localizadas nas Américas e África, constatam que o estilo de vida urbana não interfere, necessariamente, nos laços de parentesco e nas bases da solidariedade tradicional. No Brasil existem poucos trabalhos que apontem o impacto, na subjetividade pessoal, que adquire o processo de migração para o indígena, tratado geralmente como um fenômeno coletivo que parece culminar com a inserção definitiva em uma nova estrutura econômica e social (Paladino, 2006).

A passagem por Salvador, ou por outros centros urbanos para alcançar a formação universitária não acarreta o estigma de marginalizado aos estudantes, tal como no caso descrito por Florestan Fernandes (1975). São outros tempos, afinal.

\footnotetext{
${ }^{10} \mathrm{~A}$ PEC 215 é uma Proposta de Emenda à Constituição, em tramitação, que passa a incluir entre as competências exclusivas do Congresso Nacional a aprovação da demarcação das terras tradicionalmente ocupadas pelos índios e a ratificação das demarcações já homologadas, estabelecendo que os critérios e procedimentos de
}

Entre os Tuxá, por exemplo, quando um jovem é selecionado no vestibular, as lideranças encarnadas em seus líderes solicitam que o estudante assine uma espécie de pacto ou contrato com a comunidade, compromentendo-se a retornar, quando os estudos findarem. Essa é uma entre outras tantas estratégias formais que poderão ser adotadas para que essa população migrante não se afaste da comunidade, nesse modelo de deslocamento alternativo praticada, especialmente, pelas novas gerações oriundas das comunidades tradicionais.

Nesta situação de migração temporária poderão ser construídas importantes redes de relações com não indígenas -- a exemplo de relações de trabalho, amizade, vizinhança com agentes estratégicos, políticos e administrativos, partidos políticos, órgãos governamentais e organizações não governamentais -- que poderão contribuir com os interesses da comunidade. Um exemplo ilustrativo é o movimento que os estudantes indígenas realizaram em Salvador, contrário à PEC $215^{10}$, com manifestações constantes no campus da UFBA e em locais não institucionais, como em áreas centrais da cidade.

demarcação serão regulamentados por lei (Câmara dos Deputados, 2015. Disponível em: http://www.camara.gov.br/proposicoesWeb/fichad etramitacao?idProposicao $=1050804$. Acesso em: 15/09/15). 
O período em que os estudantes permanecem em Salvador é marcado por um intenso fluxo entre essa cidade e suas comunidades, uma boa demonstração de que a nova residência não implica em um rompimento com as relações e os assuntos da aldeia. Ao contrário, umas e outros estão em permanente conexão com aqueles tecidos na cidade, muito embora, no início, o apoio da comunidade de pertencimento possa revelarse fundamental: a título de exemplo, um estudante tuxá foi passar um fim de semana na aldeia, a pedido da família, para que pudesse fazer um tratamento espiritual, que o fortalecesse e assegurasse o retorno para a capital.

Meruca (Cremilda Braz), mãe de Arissana Braz e Anari Braz, conta que sempre que podia estava em Salvador, ocasiões em que trazia artesanato ${ }^{11}$ para vender e, assim, contribuir para a permanência das filhas.

Às vezes eu quando ia para lá eu levava um colar, [ou] mandava levar, lá elas vendiam para as colegas delas, era a única coisa que eu poderia fazer... Às vezes eu ia também pra lá, e vendia também, era uma ajuda também, ficava lá com elas, era assim. Mas essas meninas foi uma luta, viu, foi uma luta. Foi Deus mesmo, mas depois, graças a Deus, Deus tomou a frente! E elas

\footnotetext{
${ }^{11} \mathrm{O}$ artesanato aparece como uma fonte de renda cada vez maior para muitos indígenas nas grandes cidades. Além de ser uma fonte de renda para muitas famílias ali estabelecidas, está se constituindo em um importante item criador de visibilidade social e, consequentemente,
}

estudaram, aí eu falo, meu Deus eu não quero que vocês estudem mais não, porque menina, eu ficava muito preocupada, tinha noite, meu pai, que eu pensava: o que que essas meninas estão fazendo? mas elas tinham a cabeça delas erguida. (Meruca)

Nos breves ou pouco mais longos retornos às comunidades, muitas atividades podem ser desenvolvidas pelos estudantes. Daniel, Letícia e Raiane trabalham em barracas de praia, nas férias; Genilson Taquary construiu uma barraca de praia, do mesmo modo, nas férias. Além das férias, feriados prolongados e períodos de greve na universidade, alguns festejos são também priorizados para breves retornos, como as festas de fim de ano, festas juninas, e situações especiais, como os Jogos Indígenas Pataxó que ocorrem em Coroa Vermelha. A participação em encontros de mobilização social e política também constituem bons motivos, do mesmo modo que viagens a outros locais (a exemplo de Brasília), para representar as comunidades, ou eventos durante os quais possam também fazer trabalho de campo no interior das comunidades.

A adaptação a Salvador poderá ser um dos empecilhos à permanência na universidade, especialmente no caso de

mobilizador político e propiciador de direitos (Albuquerque, 2011). 
mulheres e com filhos. Pâmela, estudante pataxó, tinha na época uma filha de dois anos e retornou à aldeia, por não haver se adaptado à nova situação. Sirlene, formada em enfermagem, veio para Salvador, engravidou, voltou para a aldeia e, pouco depois, retornou para terminar o curso, deixando seu filho, no período, com o ex-companheiro.

A ausência de espaços que lhes permita expressar a religiosidade indígena mediante a prática dos rituais está entre os fatores de cuja falta mais se ressentem, em Salvador, os estudantes pankararu, pataxó e tuxá.Vanessa Carvalho, estudante pataxó, afirma que do que mais se sente privada no cotidiano de Salvador "é da sua comunidade de origem, das belezas naturais, da minha família, amigos e parentes, dos projetos dos quais participava, dos rituais, de estar próxima a minha cultura". Dentre as atividades coletivas praticadas nas comunidades, os rituais talvez sejam os mais acionados, cuja privação deve colaborar para a estadia solitária.

Outro fator sempre ressaltado pelos estudantes é a alimentação. A dieta alimentar sempre será uma importante marca de distinção étnica. De modo geral, inicialmente eles estranham um pouco o cardápio servido nos restaurantes universitários e algumas das receitas próprias ao recôncavo baiano elaboradas em Salvador, que se destacam pelo uso generoso do azeite de dendê. Convidados a participar de encontros em outras cidades ou Estados, preocupam-se com a alimentação, principalmente se estarão presentes itens que representam a base da sua alimentação, i.e., feijão, arroz, algum tipo de carne e farinha. No terceiro encontro de estudantes indígenas, em Florianópolis (SC), realizado em 2015, os estudantes salientaram a necessidade das universidades pensarem em um cardápio diferenciado para indígenas e quilombolas, uma vez que a alimentação utilizada no processo de migração estudantil desconsidera os seus hábitos alimentares. A grande presença de alimentos industrializados, frituras, sódio, refrigerantes, associada à menor frequência de atividades físicas (andar a pé, de bicicleta) e laborais (atividades domésticas variadas), comparativamente ao que ocorre nas aldeias, impõem desequilíbrios à saúde, como o sobrepeso e o aumento da pressão arterial, como sinalizou uma estudante, participante do referido encontro, da Universidade Federal do Oeste do Pará (UFOPA), ao afirmar que a razão para estar "mais gordinha" tinha a ver com a sua inserção na universidade, devido à alteração dos seus hábitos alimentares.

Os estudantes pataxós tentam, estrategicamente, atualizar a sua memória gustativa com o que temos (eu e eles) designado de "almoços na tradição", durante 
os quais vários pratos e bebidas são preparados dentro da tradição pataxó. Habitante no litoral, a base da alimentação do povo Pataxó está associada a peixes, que são preparados na folha de bananeira; crustáceos, como caranguejos; paçoca feita de puba de mandioca; beijus e cauim produzidos mediante a fermentação da mandioca. Tal dieta, bem litorânea, nem sempre agrada, por outro lado, o paladar dos estudantes das comunidades do norte da Bahia.

Em conversa com alguns dos estudantes, uma certa memória mítica de um passado "tradicional" às vezes também é revelada. Nesses momentos são lembrados os tempos da vida livre de quando eram mais novos, circulando e brincando pela aldeia. Percebo que, ao se reunirem, essas memórias são inevitavelmente evocadas, em um exercício de compartilhamento que, simultaneamente, atualizam-nas e reforçam os vínculos de pertencimento. O relato de Daniel, estudante pataxó, é eloquente:

Fui criado em total contato com a natureza, tive a melhor infância que uma pessoa pôde ter. Cresci brincando nos rios, nas matas e a aplaudir tudo de belo que tem aquele lugar. Hoje, distante, eu dou um valor ainda maior a tudo aquilo que me faz falta. O pôr do sol é diferente, o ar respirado é diferente, as manhãs são diferentes, as noites, a lua. Tenho convicção de que aquele lugar é único [...] Cresci comendo bichos do mato, que meu pai matava, ainda mata, para nos alimentar, mas de uma maneira organizada [...] Até meus 7 anos de idade, época em que ingressei na escola, eu tinha muita dificuldade em conviver com pessoas diferentes, muita gente, pois eu sempre vivi isolado naquele lugar, eu era muito acanhado, meu único amigo era meu irmão, que é um ano mais velho do que eu.

O apego aos laços e às relações nas aldeias convive com a sempre presente predisposição de estabelecimento de novas relações pessoais, de novos e bons amigos. É oportuno lembrar que boa parte das comunidades indígenas do Estado da Bahia mantém, de alguma forma, contato frequente com centros urbanos, quando não estão neles inseridas, como são os casos da aldeia pataxó de Coroa Vermelha (extremo sul da Bahia) e da aldeia Tuxá de Rodelas (região norte do Estado). Em geral os contatos são motivados por questões de saúde, educação, obtenção de beneficios sociais, como aposentadoria, venda de artesanato, lazer e fins religiosos.

$\mathrm{Na}$ atual conjuntura histórica, a instrução escolar formal se apresenta nas áreas indígenas, em geral, como um dos principais fatores de interlocução com a sociedade nacional brasileira, implicando em um forte vínculo com essa mesma sociedade. Há que considerar que a relação com a sociedade nacional, por meio da educação, muito provavelmente já tenha sido experimentada em outros episódios de escolarização, o que poderá 
atenuar o impacto com a nova realidade. Tem sido também a partir da escola diferenciada que os estudantes indígenas tentam articular os valores tradicionais indígenas aos que a estes são externos e estranhos. É bastante emblemático o fato de que, constantemente, os estudantes, especialmente os vinculados a projetos de extensão (Projetos de Educação Tutorial - PETs e outros), realizem atividades nas aldeias cujo propósito é o de recolher e estudar histórias e experiências dos mais velhos, como uma mediação entre essas gerações e sua comunidade (lá) e Salvador (cá).

Esse vínculo com a comunidade distingue, significativamente, a presença dos estudantes indígenas cotistas dos demais cotistas que ingressam, na universidade, por origem racial ou renda. A relação permanente que mantêm com seus locais de origem assegura-lhes um "retorno mais eficaz nas ações afirmativas", como afirma Jocélio Santos (inf. pessoal). Comparativamente, a ascensão vertical não será tão almejada quanto o que ocorre com os estudantes negros cotistas nos Estados Unidos, por exemplo, que acabam sendo cooptados pelas políticas de ações afirmativas, ao neutralizarem o pertencimento ao grupo racial em troca de um sistema de inclusão que privilegia a competição entre os

${ }^{12} \mathrm{O}$ sistema de cotas nos Estados Unidos utiliza um sistema de pontuação com base na categoria racial que é combinado sempre com a análise e a admissão de ingresso decidida caso a caso, significando que cada estudante negro que entra por ações afirmativas ganhauma concorrência frente a outros concorrentes negros $^{12}$ (Carvalho, 2006). No Brasil, podemos pensar que a noção recorrente de comunidade entre os povos indígenas contribui para a formação do sujeito, e, por sua vez, para a produção de uma auto-imagem e consciência de si ontologicamente mais seguras, não obstante a trajetória de exploração, expropriação e estigmatização a que foram submetidos, historicamente. Carvalho acredita que para a luta dos negros não se tornar assimilacionista nem tampouco conservadora, é importante que incorpore como aliados a comunidade bem mais restrita, mas estruturada, que é a dos índios (I $b$. p. 136), como também possa aprender com eles como fortalecer esse duplo pertencimento: acadêmico e étnicocomunitário.

Na universidade, é bem verdade, esta relação será também colocada à prova, já que representa um dos diferenciais entre a formação do estudante cotista indígena aldeado e as outras categorias de ingresso. Especialmente nos cursos de alto prestígio, como no curso de direito, os estudantes relatam sofrer assédio dos professores, no sentido de não retornarem para as suas comunidades e orientarem suas carreiras para o mercado, visando o sucesso profissional desvinculado do retorno. Juliana, estudante

estudantes negros que foram considerados menos aptos que ele. Na política brasileira, os estudantes negros e índios entram pelas cotas na forma de um contingente (Carvalho, 2006, p. 182-83). 
nessa área, refere a um professor que, constantemente, lhe dá conselhos para não considerar sua relação com a comunidade, lembrando-lhe que a sua entrada e consequente formação universitária é seu mérito próprio, e que, portanto, não deve se sentir compelida a retornar.

Mas o que significa a formação superior para um povo indígena e a repercussão do fato para as aldeias? Esse é um dos questionamentos que Gomes e Miranda (2014) fazem em relação aos cursos de licenciatura da Universidade Federal de Minas Gerais (UFMG). A decisão de sair da aldeia é parte de um compromisso tácito com o grupo, e que poderá até mesmo ser afiançado por suas lideranças. Ou, como no caso dos estudantes tuxá, compromisso ratificado por um acordo escrito firmado por solicitação das lideranças da comunidade. Dessa forma podemos pensar no jovem estudante indígena como um "indivíduo coletivo".

Certamente que após a inserção na universidade, esta representação / identidade poderá mudar, o que parece estar mais relacionada com a área ou campo do saber em que cada estudante está inserido. Sobre essa questão, há alguns cursos que, no dizer do líder Agnaldo Pataxó Hãhãhãe, "maltrata” os povos indígenas, no sentido de que acabam

\footnotetext{
${ }^{13}$ Elias e Scottson estudaram os habitantes de um bairro operário inglês que eram bem sucedidos externamente, enquantoos que permaneciam consideravam que a sua ligação com os que haviam
}

produzindo um ethos que afasta o estudante do interesse coletivo, incentivando o mérito individual.

Aqueles que permanecem na comunidade geralmente nutrem um sentimento de orgulho pelos que estudam "na cidade". De modo geral, a comunidade reconhece quem são, o que fazem na universidade, onde moram, com quem moram, quando retornarão, mesmo daqueles que não são parentes, ou parentes próximos: se compõem a comunidade, haverão sempre de ser parentes de alguém. "A circulação de informação sobre essas pessoas pode ser entendida como o tipo de "fofocas elogiosas", descritas por Elias e Scottson ${ }^{13}$ (2000, p. 123, apud Paladino, p. 130). Em visita à Coroa Vermelha para trabalho de campo, ao procurar os pais de alguns dos estudantes para encetar conversas sobre a situação dos seus filhos em Salvador, encontrei Dona Maria, mãe de Juliana e Rutian. Dona Maria é vendedora de artesanato, em sua loja, e em meio a diversos produtos comercializados encontro, afixados em uma das paredes, alguns retratos de formatura de estudantes indígenas, dois dos quais pela UFBA. Pergunto-lhe sobre as fotos, e ela, orgulhosamente, afirma que são jovens parentes que já se formaram e que

ascendido socialmente elevava seu status (Paladino, 2006, p. 130). 
representam um orgulho para a comunidade, mencionando que, em breve, as fotos das suas filhas estarão ali.

Afixados à parede, fotos de Washington José dos Santos (pataxó hãhãhãe) e João Bernardo Junior (pataxó), formados em direito e educação física, respectivamente, pela UFBA.

A escolarização provê conhecimentos e habilidades específicas além de contribuir para a construção de uma nova identidade social -- a de "estudantes indígenas". Em contrapartida, ingressar na universidade não parece ter significado, para os estudantes que tenho acompanhado, uma ruptura afetiva e cultural com os laços e costumes de cada povo. Em geral, a vida na capital tem reforçado os projetos trazidos "de casa", devidamente contextualizados quanto às possibilidades concretas para sua realização. Não consegui perceber, de modo evidente, uma mudança das expectativas, valores e costumes desses jovens estudantes no decorrer dos seus percursos acadêmicos; antes, registrei que as intenções primeiras de estudar e, posteriormente, trabalhar, persistiram, assim como o desejo sempre presente de retornar às suas comunidades.

\footnotetext{
${ }^{14}$ Através dos Decretos 7.335 e 7.336 de 19/10/2010, a responsabilidade da saúde indígena foi transferida da FUNASA para a SESAI, transferindo as ações da saúde indígena ao Ministério da Saúde por meio das
}

\section{A Ocupação da Cidade e as Políticas Públicas e de Permanência na Universidade}

A vida na cidade requer que as populações indígenas nela inseridas priorizem suas demandas, a exemplo de moradia, educação e saúde. Um dos pontos de mobilização dos povos indígenas nas cidades é justamente a questão do atendimento à saúde, que, devido à falta de clareza jurídica, ainda enfrenta muitos obstáculos por parte dos órgãos responsáveis, o que tem levado muitos povos a se organizar, de forma autônoma e em parceria com órgãos públicos e sociedade civil a fim de construir políticas públicas que deem conta das novas especificidades, como aquela acarretada pelo deslocamento rural/urbano. Embora, de acordo com a Fundação Nacional de Saúde (FUNASA) ${ }^{14}$, a determinação seja a de assistir somente indígenas de aldeias reconhecidas pela FUNAI, os que passam a viver em centros urbanos, fora da Terra Indígena (TI), deverão ser atendidos pela rede pública convencional (Carvalho, 2007, apud Albuquerque 2011).

Uma grande dificuldade para o atendimento aos indígenas nas cidades é o problema de como reconhecer quem é

subdivisões em Departamento de Gestão de Saúde Indígena, Departamento de Atenção à Saúde Indígena e Distritos Sanitários Especiais Indígenas. 
ou não indígena. $\mathrm{O}$ modelo mais conhecido para remediar esse conflito vem sendo aplicado em São Paulo, pelos Pankararu do Real Parque. Tal modelo preza pelo conhecimento de suas redes de parentesco, os contatos deles com outros povos é usado pela FUNASA para conseguir identificar esta população que vive espalhada pela cidade. Além dos próprios Pankararu, a associação que os representa em São Paulo, a SOS-CIP, também cadastrou os demais indígenas oriundos do nordeste (Carvalho, 2007, apud Albuquerque, 2011. p.72).

Com a vida de índio "des-aldeado", devido à migração temporária para realização de estudos, os estudantes não têm acesso à saúde diferenciada em Salvador, utilizando, então, os serviços de saúde prestados pela UFBA, SUS (Sistema Único de Saúde) ou atendimento particular. $\mathrm{Na}$ sua avaliação, o serviço público de Salvador é muito inferior ao da aldeia, e chegam a afirmar que "não [lhes] é permitido ficar doente em Salvador", frente às dificuldades de assistência médica. Essa é uma questão relevante, que tem mobilizado os indígenas no sentido de obter reconhecimento e garantia dos seus direitos diferenciados. Muitas vezes a saída tem sido recorrer a organizações e associações, como forma de criar instrumentos legais que os representem, junto ao poder público, como uma comunidade indígena fora de uma Terra Indígena (TI) (Albuquerque, 2011). De

\footnotetext{
${ }^{15}$ Albuquerque (2011, p. 186) conta que após o reconhecimento por parte da FUNAI dos Pankararu do Real Parque enquanto uma população indígena migrante (desaldeada) residente em São Paulo, a
}

acordo com a Secretaria Especial de Saúde Indígena (SESAI), só serão assistidos os indígenas aldeados em suas comunidades, não os podendo legalmente assistir quando estão fora ${ }^{15}$. Algumas lideranças têm defendido que os estudantes indígenas, a rigor, não estão fora das aldeias, mas apenas, temporariamente, distantes.

A adaptação à cidade constitui, pois, um grande obstáculo a ser superado, cotidianamente, avaliada, porém, positivamente, em face da possibilidade de vivenciar outras experiências culturais e trocar informações, expandindo, assim, a percepção, em um movimento em que ao mesmo tempo que aprendem também ensinam, em uma "verdadeira troca de saberes", como afirma a estudante Vanessa. Uma outra relatou a sua perplexidade ao andar de ônibus por Salvador, passar por avenidas e grandes prédios que contrastam, tão fortemente, com as suas lembranças da infância na aldeia.

Os bairros da Federação e do Canela, de classe média, e o Engenho Velho da Federação e o Alto das Pombas, mais populares, têm sido os preferidos para moradia pelos estudantes, por estarem próximos aos campi. A UFBA não tem residência estudantil para estudantes

FUNASA realizou cadastro dessa população para atendimento médico, mediante o PSF Indígena. 
indígenas, e até então não houve nenhuma experiência de ocupação, por eles, desse espaço institucional. $\mathrm{O}$ que ocorre é o aluguel de casas, que costumam ser partilhadas entre estudantes da mesma família e a comunidade, geralmente. Os aluguéis variam entre $\mathrm{R} \$ 600,00$, para casas, e R\$1.500,00, para apartamentos (incluído condomínio). A maior parte do campus da UFBA fica localizada nessa região da cidade, o que explica a preferência pelo local, cujo deslocamento se faz a pé, para muitos outros campi, localizados no entorno. A proximidade facilita o contato entre eles, em determinados momentos, como os de lazer, nos fins de semana. Vale ressaltar que, por ocasião do ingresso, não existe, por parte da universidade, uma política de acolhimento diferenciada para os estudantes indígenas. Eles serão apenas apoiados, mais diretamente, pela Pró-Reitoria de Ações Afirmativas e Assistência Estudantil $(\text { PROAE })^{16}$.

A PROAE possui alguns auxílios que contribuem para a permanência dos estudantes na universidade, apoiando-os a

\footnotetext{
${ }^{16}$ De acordo com a UFBA, os auxílios geridos pela PROAE-UFBA devem contribuir para a permanência dos estudantes na universidade, visando acolher, integrar e apoiar o cotidiano da vida universitária, ao reconhecer e viabilizar direitos necessários para o enfrentamento das adversidades sociais e para colaborar com os processos de aprendizagem do corpo discente. Os auxílios e benefícios da PROAE estão em consonância com o Programa Nacional de Assistência Estudantil (PNAES), instituído pelo decreto $\mathrm{N}^{\circ} 7.234$, de 2010, que estabelece que todos
}

partir da análise do perfil e das suas necessidades específicas, para que haja uma melhor condução do percurso acadêmico. Os auxílios são voltados para aqueles em situação de vulnerabilidade socioeconômica ou que apresentem dificuldades de outra ordem, passíveis de colocar em risco a permanência na universidade. A PROAE dispõe de uma linha de auxílio que compreende desde bolsa acolhimento (auxílio financeiro nos dois primeiros meses de ingresso, no valor de $\mathrm{R} \$ 400,00$, para estudantes em situação de vulnerabilidade social); serviço de residência universitária e de hospedagem (espaços mantidos pela universidade para moradia de estudantes que não tenham residência em Salvador, garantidas três refeições diárias); auxílio moradia (repasse financeiro mensal no valor de $\mathrm{R} \$ 400,00$ e mais $\mathrm{R} \$ 150,00$ para o auxílio café da manhã para estudantes que não tenham residência em Salvador); bolsa de apoio aos estudantes com deficiência (auxílio financeiro no valor de $\mathrm{R} \$ 400,00$ para contribuição nas despesas referentes à aquisição de material específico); serviço de

os estudantes de graduação das instituições federais de ensino superior têm direito a ser assistidos, observando as necessidades e perfis de cada grupo, especialmente aqueles oriundos da rede pública de ensino, em situação de vulnerabilidade socioeconômica e com renda familiar per capita de até um salário mínimo e meio, incluindo ainda os estudantes pretos, pardos, indígenas e quilombolas (https://www.ufba.br/noticias/comunicado-aoestudante-em-fase-de-inscri\%C3\%A7\%C3\%A3ono-sisu. Acesso em: 20/10/2015). 
alimentação (garantia de duas refeições diárias no Restaurante Universitário); auxílio transporte (auxílio no valor de $\mathrm{R} \$$ 84,00 , visando subsidiar despesas com deslocamento) e creche escolar.

Devido à grande procura, esses auxílios representam um "bem limitado", sendo bastante disputados pelos estudantes em situação de vulnerabilidade sócioeconômica. Com os estudantes indígenas não é diferente, geralmente acionam os auxílios do bolsa acolhimento, no primeiro mês em que chegam a Salvador, do Restaurante Universitário e do auxílio transporte. Como existe uma forte concorrência para o serviço de residência e hospedagem, com uma longa fila de espera, nenhum estudante morou na residência universitária nesses dez anos de ações afirmativas da UFBA.

Estes auxílios representam, inquestionavelmente, uma significativa colaboração para a permanência dos estudantes universitários, não obstante ainda estejam bastante aquém do rol de necessidades desse público. No caso dos estudantes indígenas, a ausência de uma residência universitária específica gera mais um fator de ponderação sobre a vinda para estudar na UFBA: praticamente para todos os estudantes cotistas aldeados que

\footnotetext{
${ }^{17}$ O Programa de Bolsa Permanência (PBP) foi criado pela Portaria $n^{\mathbf{o}} 389$ para estudantes de baixa renda,
}

aceitaram o desafio, esta foi a grande prova de fogo: conseguir um local de moradia na capital. Este tem sido um dos principais pleitos dos estudantes indígenas que passaram pelas três gestões da UFBA, durantes os quatorze anos do programa.

A exemplo de outras universidades, como a Universidade Estadual de Feira de Santana (UEFS) e Universidade de São Carlos (UFSCAR), o desejo dos estudantes indígenas é que possam ter um local de residência passível de ser compartilhado com seus parentes. Quando perguntados sobre a importância de uma residência indígena, mencionam o fato de terem hábitos culturais específicos, como a realização de rituais (toré, auê), cultivo de pequenas plantações, criação de pequenos animais. Citam também as visitas dos parentes e a realização de festejos. Apesar do pleito e da sinalização positiva, por parte de representantes institucionais, de construção de uma residência universitária indígena, tal não deverá se concretizar a curto prazo, dado que a UFBA atravessa uma severa crise, não havendo disponibilidade de local e recursos.

Em 2013, com o Programa Bolsa Permanência $^{17}$ (PBP), os estudantes indígenas passaram a dispor de certo conforto material e estabilidade com relação à moradia. $\mathrm{O}$ aluguel de casas compartilhado

indígenas e quilombolas que façam cursos de graduação em universidades federais. 
com os estudantes parentes continuou a ser realizado, agora com um pouco mais de comodidade. A bolsa concedida pelo Programa para estudantes indígenas e quilombolas, no valor de $\mathrm{R} \$ 900,00$, pode ser acumulada com outras bolsas ou auxílios. Os estudantes da UFBA geralmente acumulam esse valor com valores percebidos em estágios nas suas áreas de formação ou em outras bolsas, como o bolsa PET, o que torna a permanência em Salvador ${ }^{18}$ menos aflitiva. Para João Paulo "quanto mais recurso financeiro o aluno consegue, mais melhora sua qualidade de vida na universidade, e, como consequência, seu desempenho acadêmico". Ele ainda afirma que os estudantes indígenas e quilombolas não têm conseguido acumular o auxílio moradia da UFBA, sob a justificativa de que já recebem a bolsa permanência, o que lhe parece representar um veto aos direitos dos estudantes. E quando conseguem, por outro lado, a possibilidade de acumular a bolsa com outros auxílios tem produzido também novos hábitos de consumo, como a aquisição de cartões de crédito, de itens de vestuário e acessórios, em lojas de departamento, e aparelhos tecnológicos, como celulares e computadores.

\footnotetext{
${ }^{18}$ De acordo com a PROAE, a UFBA tinha em 2015 , 45 estudantes indígenas que recebem bolsa permanência.
}

Os programas de ações afirmativas das universidades, a rigor, deveriam ser compostos por ações que viabilizassem o acesso e a permanência. $\mathrm{O}$ que as experiências demonstram, todavia, é que a permanência, muitas vezes, torna-se um dos entraves a esses programas, pois as universidades não possuem uma estrutura que possa favorecê-la.

\section{Considerações Finais}

Até há bem pouco tempo, falar sobre índios que vivem no contexto urbano significava tratar de fenômenos resultantes de processos de expulsão, que compeliam comunidades ou parte delas a migrar, inicialmente, das terras tradicionais para as cidades próximas, e, posteriormente, para centros urbanos que se constituem em polos históricos de atração de migrantes, como é o caso da cidade de São Paulo, a exemplo do que aconteceu com os índios Pankararu do sertão de Pernambuco. Ou como os Terena que, em razão da redução dos seus territórios tradicionais, migraram em grande parte para Campo Grande, capital do Mato Grosso do Sul, onde constituíram um bairro (Araújo et alii, 2006 p.70-1). 
Em todo o Brasil veremos que as políticas públicas gestadas para as populações indígenas foram sempre formuladas para assistir as comunidades a partir dos seus territórios, no âmbito do conceito de reserva/aldeia indígena ou Território Indígena, não havendo programas de assistência em situações de deslocamento. A vida na cidade acaba por produzir "uma espécie de limbo jurídico", dificultando o acesso a direitos, na medida em que a legislação foi pensada para proteger os índios que vivem em seus territórios tradicionais ou afastados do convívio não indígena (Ib., p.71). Como afirma Ana Valéria Araújo (Ib.), morar em cidades tem sido equivocadamente entendido como um dado revelador da perda da intenção de manter a condição de indígena, o que implicaria em uma certa renúncia tácita à proteção especial garantida pela legislação, além da desconsideração dos processos históricos, dando margem a novos tipos de preconceito ainda não vislumbrados pelo ordenamento jurídico.

A migração urbana estudantil proporciona novas formas de perceber a inserção de indígenas na cidade, dado que, não obstante possam ser reconhecidas as dificuldades de manutenção de certos direitos acessados em suas comunidades, será considerada uma migração mais positiva, não tão pautada na ausência (de traços e condições), mas no próprio deslocamento. Nos últimos dez anos, no Brasil e na América Latina, essa nova forma de migração característica da juventude estudantil configurará um novo formato de ocupação das cidades pelas populações indígenas. A vida na cidade produzirá novos hábitos, seja de consumo, de diversão, de disciplina corporal, de gostos musicais (como o estudante tuxá que fez um curso de $\mathrm{Dj}$ ), de contato com outras concepções de mundo e categorias socioculturais. A esse propósito, a estudante pankararu relata como foi estranho para ela deparar-se, pela primeira vez, com problematizações sobre as diferenças e desigualdades de gênero, uma vez que em sua comunidade as distinções de gênero se apresentam -- é a sua suposição -como naturais ou autoevidentes. Novas demandas também têm surgido, como a de acompanhamento psicológico para estudantes indígenas, da UFBA e de outras instituições de ensino superior.

"Descobrindo a Bahia, enquanto me descubro", é a legenda das fotos produzidas por uma estudante indígena em visita a um museu em Salvador. O ingresso na UFBA parece se transformar em um lugar de deslocamentos, de vivência profunda da experiência migratória e tudo o mais que ela possa proporcionar, e requerer, como a auto descoberta de jovens atores sociais 
defrontados com um novo sistema de significados.

A relação estabelecida com as comunidades de origem ainda é, do meu ponto de vista, a chave para a experiência diferenciada que vivenciam os estudantes indígenas nas universidades.

A partir de 2013, com a adoção da Lei de Cotas, a instituição do Programa Federal Bolsa Permanência e do ENEM e SISU, tem-se o que considero corresponder a uma outra etapa das ações afirmativas nas universidade brasileiras. Entre 2014 e 2015 foram selecionados mais estudantes que em todos os oito anos do programa de ações da UFBA, totalizando 65. Esse aumento é resultado dessas novas políticas públicas e da mobilização efetuada pela juventude indígena ingressa, que tem se esforçado para que seus parentes tenham também acesso a um ensino superior de qualidade.

Com a destituição ilegítima do governo da presidenta Dilma Rousseff em 2016, os programas de políticas públicas voltadas para a inclusão no ensino superior passaram a sofrer sérios riscos de serem extintos, a exemplo do corte recente, em junho de 2018, no Programa de Bolsa Permanência para estudantes indígenas e quilombolas, levando esses estudantes a uma grande mobilização em Brasília para que o governo reconsiderasse. Tudo indica, a partir do cenário atual, que os próximos anos continuarão sendo dias de luta pelo ingresso e permanência na universidade.

\section{Referências bibliográficas}

ALBUQUERQUE, Marcos Alexandre S. O regime imagético Pankararu (tradução intercultural na cidade de São Paulo) [tese]. Universidade Federal de Santa Catarina. Programa de Pós-Graduação em Antropologia Social. Florianópolis, 2011.

ARAÚJO, Ana Valéria Araújo (et alii). Povos Indígenas e a Lei dos "Brancos": o direito à diferença. Brasília: Ministério da Educação, Secretaria de Educação Continuada, Alfabetização e Diversidade; LACED/Museu Nacional, 2006.

BOURDIEU, Pierre. Questões de sociologia. Rio de Janeiro: Marco Zero. 1983.

CARVALHO, José Jorge. Inclusão étnica e racial no Brasil. São Paulo: Attar Editorial, 2006.

CARVALHO, Priscila D. de. Ín_d_i_o_s_ _a__C_i_d_a_d_e_, 2007. Disponível em: http://www.webbrasilindigena.org/?page_id $=177$. Acesso em: 19/01/2015.

DUARTE QUAPPER, Klaudio. ¿Juventud o Juventudes? Acerca de cómo mirar y remirar a las juventudes de nuestro continente. Revista Última Década, No 13, 2000, pp. 59-77.

Disponível em: http://www.cidpa.cl/udecada/txt/decada13/art0 4.pdf.

ELIAS, Norbert. Os estabelecidos e os outsiders. Rio de Janeiro: Jorge Zahar, 2000. 
FERNANDES, Florestan. Tiago Marques

Aipobureu: um bororo marginal. In:

Investigação etnológica no Brasil e outros ensaios. Petrópolis: Vozes, 1975.

GARCÍA ÁLVAREZ, Luis Fernando.

Jóvenes indígenas en contextos

metropolitanos. La construcción de lo juvenil en una comunidadmixtecaenel Área Metropolitana de Monterrey, Nuevo León. (Dissertação). Escuela Nacional de Antropología e História, Cidade do México, 2012.

GOMES, Ana Maria R.; MIRANDA, Shirley Aparecida de. "A formação de professores indígenas na UFMG e os dilemas das "culturas" entre os Xacriabá e os Pataxó. " In: CARNEIRO DA CUNHA, M.; CESARINO, P. N. (orgs). Políticas culturais e povos indígenas. São Paulo: Cultura Acadêmica, 2015, pp.455-84.

OLIVEIRA, João Pacheco. Viagens de ida, de volta e outras viagens: os movimentos migratórios e as sociedades indígenas. Travessias, jan./abr., 1996, pp. 510.

PALADINO, Mariana. Estudar e experimentar na cidade: Trajetórias sociais, escolarização e experiência urbana entre "Jovens" indígenas ticuna, Amazonas. (Tese). Programa de PósGraduação em Antropologia Social, Museu Nacional, Universidade Federal do Rio de Janeiro. 2006.

SANTOS, Jocélio Teles dos. Introdução. In: SANTOS, J. T. (org). Cotas nas universidades: análise dos processos de decisão. Salvador: CEAO, 2012, pp. 9-15.

SOUZA, Natelson Oliveira de. A HERANÇA DO MUNDO: história, etnicidade e conectividade entre jovens
Xokó”. (Dissertação). Programa de PósGraduação em Antropologia, Universidade Federal da Bahia, Salvador, 2011.

TASSINARI, Antonellaet al. "A presença de estudantes indígenas na Universidade Federal de Santa Catarina: um panorama a partir do Programa de Ações Afirmativas PAA/UFSC." Século XXI. Revista de Ciências Sociais, v.3, no 1, jan./jun. 2013, pp.212-236.

TCHAM, Ismael. Estar, ficar e retornar: estudantes africanos no Brasil e os dilemas da migração. (Tese). Programa de Pós-graduação em Antropologia, Universidade de Pernambuco, 2016.

URTEAGA, Maritza Castro Pozo. La construcción juvenil de larealidad. Jóvenes mexicanos contemporaneous. UAM-Juan Pablos Editor, México, 2011, 188. 